\title{
Blockade of IL-2 Receptor Suppresses HTLV-I and IFN- $\gamma$ Expression in Patients with HTLV-I-Associated Myelopathy/Tropical Spastic Paraparesis
}

\author{
Naomi Fukushima ${ }^{1}$, Yoshihiro Nishiura ${ }^{2}$, Tatsufumi Nakamura ${ }^{1}$, \\ Shigeru Kohno ${ }^{1}$ and Katsumi Eguchi ${ }^{2}$
}

\begin{abstract}
Objective Th1 activation based on a high HTLV-I proviral load is one of the characteristic immunological abnormalities in the peripheral blood lymphocytes of patients with HTLV-I-associated myelopathy/tropical spastic paraparesis (HAM/TSP). To clarify the cause of this abnormality with the potential to be one of the therapeutic targets, we analyzed the involvement of interleukin-2 (IL-2)/IL-2 receptor (IL-2R) signaling in HTLV-I and interferon- $\gamma$ (IFN- $\gamma$ ), which is a representative Th1 cytokine, expression in peripheral blood $\mathrm{CD}^{+} \mathrm{T}$ cells from HAM/TSP patients.

Patients and Methods Twelve patients with HAM/TSP were included in the study. After the peripheral blood $\mathrm{CD}^{+} \mathrm{T}$ cells were treated in cultures under the presence of each anti-IL-2R $\alpha, \beta$, and $\gamma$ blocking antiboby for 48 hours, both HTLV-I p19 antigen and IFN- $\gamma$ levels in the culture supernatants were measured using ELISA methods. To check the influence on cell proliferation under these culture conditions, the numbers of viable cells were simultaneously determined by MTS assay.

Results Treatment with anti-IL-2R $\alpha$ blocking antibody, but not anti-IL-2R $\beta$ or anti-IL-2R $\gamma$ blocking antibody, suppressed HTLV-I p19 antigen expression levels. In addition, treatment with all types of anti-IL-2R blocking antibodies also suppressed IFN- $\gamma$ expression levels. All of the types of anti-IL-2R blocking antibodies did not inhibit the proliferation.

Conclusion These results indicate that IL-2/IL-2R signaling is involved in HTLV-I and IFN- $\gamma$ expression on peripheral blood $\mathrm{CD} 4^{+} \mathrm{T}$ cells from HAM/TSP patients, suggesting that the interruption of this signaling has therapeutic potential against HAM/TSP in patients with the focus on the down-regulation of Th1 activation based on a high HTLV-I proviral load in the peripheral blood.
\end{abstract}

Key words: HAM/TSP, IL-2, IL-2 receptor, HTLV-I, Th1, IFN- $\gamma$

(DOI: 10.2169/internalmedicine.46.6118)

\section{Introduction}

Human T lymphotropic virus type I (HTLV-I)-associated myelopathy/tropical spastic paraparesis (HAM/TSP) is chronic progressive myelopathy characterized by bilateral pyramidal tract involvement and sphincteric disturbances (1). The main pathological feature of HAM/TSP is chronic inflammation of the spinal cord (2); however, it remains unclear why such chronic inflammation is induced in only a small proportion of HTLV-I-infected individuals.

Numerous studies have revealed immunological abnormalities related to a high HTLV-I proviral load in peripheral blood lymphocytes from HAM/TSP patients (3). HTLV-I preferentially infects $\mathrm{CD} 4^{+} \mathrm{T}$ cells (4) and interleukin-2 receptors (IL-2R) are expressed on the surfaces of HTLV-Iinfected $\mathrm{CD}^{+} \mathrm{T}$ cells through the transactivation by HTLV-I tax (5). Although increased spontaneous peripheral blood lymphocyte (PBL) proliferation seems to be one of the most characteristic immunological abnormalities in PBL of HAM/

${ }^{1}$ Department of Molecular Microbiology and Immunology, Graduate School of Biomedical Sciences, Nagasaki University, Nagasaki and ${ }^{2}$ First Department of Internal Medicine, Graduate School of Biomedical Sciences, Nagasaki University, Nagasaki

Received for publication July 10, 2006; Accepted for publication October 1, 2006

Correspondence to Dr. Tatsufumi Nakamura, tatsu@net.nagasaki-u.ac.jp 
TSP patients (6), this phenomenon relies on the activation of the autocrine loop of $\mathrm{IL}-2 / \mathrm{IL}-2 \mathrm{R}(6,7)$ and IL-15/IL-15R (8). We previously proposed the importance of Th1 immune activation based on a high HTLV-I proviral load in the development of HAM/TSP (9) and more recently demonstrated that activation of the $\mathrm{p} 38$ mitogen-activated protein kinase (p38 MAPK) signaling pathway may involve both Th1 activation and a high HTLV-I proviral load in HAM/TSP patients (10). Although it remains unclear why p38 MAPK signaling is activated in HAM/TSP patients, p38 MAPK signaling is one of the downstream targets of IL-2 signaling $(11,12)$. Therefore, the activation of IL-2/IL-2R signaling might involve the activation of $\mathrm{p} 38$ MAPK signaling and then subsequently induce Th1 activation with the high HTLV-I proviral load observed in HAM/TSP patients. If so, interruption of IL-2/IL-2R signaling might be a therapeutic strategy for HAM/TSP. From these viewpoints, we focused our analysis on the involvement of IL-2/IL-2R signaling in HTLV-I and interferon- $\gamma$ (IFN- $\gamma$ ) expression in peripheral blood $\mathrm{CD}^{+} \mathrm{T}$ cells from HAM/TSP patients.

\section{Patients and Methods}

\section{Patients}

Twelve patients with HAM/TSP (4 men and 8 women; mean age, 57.2 years; age range, 33-76 years) were included in the study. HAM/TSP diagnosis was based on previously described criteria (13). None of the patients had been treated with immunomodulatory drugs, including corticosteroids and interferon- $\alpha$. The study protocol was explained in detail and signed informed consent was obtained from each subject before study participation. This research was approved by the institutional review boards of the authors' institutions.

\section{Separation of peripheral blood CD4 ${ }^{+} \mathrm{T}$ cells}

Peripheral blood $\mathrm{CD}^{+}{ }^{+}$-enriched $\mathrm{T}$ cells were separated, in negative selection, by the depletion of $\mathrm{CD}^{+} \mathrm{T}$ cells from macrophage/B cell-depleted mononuclear cells using magnetic beads coated with anti-CD8 monoclonal antibody (Dynal Biotech ASA, Oslo, Norway), from peripheral blood mononuclear cells as described previously (10). CD4 ${ }^{+}-$ enriched $\mathrm{T}$ cells were used as $\mathrm{CD}^{+} \mathrm{T}$ cells. Analysis of the $\mathrm{CD}^{+} \mathrm{T}$ cells using anti-CD4, anti-CD20, and anti-CD14 monoclonal antibodies showed that they were more than $90 \%$ pure with the presence of less than $1 \% \mathrm{~B}$ cells, and less than $1 \%$ monocytes as assessed by flow cytometry (Epics XL system II, Beckman-Coulter Electronics, Fullerton, CA).

\section{Treatment of peripheral blood $C D 4^{+} T$ cells with anti-IL-2R $\alpha$, $\beta$, and $\gamma$ blocking antibody}

To determine the appropriate concentration of anti-IL-2R blocking antibodies ( $\mathrm{R} \& \mathrm{D}$ Systems, Minneapolis, MN) for the suppression of HTLV-I p19 antigen and IFN- $\gamma$ expression, an IL-2-dependent HTLV-I-producing $\mathrm{T}$ cell line de- rived from a HAM/TSP patient (HCT-1) was treated with different concentrations of anti-IL-2R blocking antibodies, and the levels of HTLV-I p19 antigen and IFN- $\gamma$ in each culture supernatant were determined (data not shown). Thereafter, peripheral blood $\mathrm{CD} 4^{+} \mathrm{T}$ cells were cultured $\left(1 \times 10^{6} / \mathrm{ml}\right)$ in the presence of $10 \mu \mathrm{g} / \mathrm{ml}$ of each anti-IL-2R $\alpha$ (clone 22722), $\beta$ (clone 27302), and $\gamma$ (clone 38024) blocking antibody in RPMI 1640 supplemented with $20 \%$ fetal bovine serum (FBS) in 24-well culture plates for 48 hours. The culture medium was centrifuged $(2,500 \mathrm{rpm}, 10 \mathrm{~min})$ and the supernatant was stored at $-40^{\circ} \mathrm{C}$ until use.

\section{Measurement of HTLV-I p19 antigen and IFN- $\gamma$ levels in culture supernatants}

The level of HTLV-I p19 antigen in the culture supernatants was measured using the RETROtek HTLV p19 antigen enzyme-linked immunosorbent assay (ELISA) kit using the manufacturer's instructions (Zeptometrix Corporation, Buffalo, NY). The amount of HTLV-I p19 antigen was determined in duplicate. The minimum measurable level of HTLV-I p19 antigen was $25.0 \mathrm{pg} / \mathrm{ml}$. The IFN- $\gamma$ level in the culture supernatants was measured using an enzymeamplified sensitivity immunoassay (EASIA) kit according to the manufacturer's instructions (Medgenix, Fleurus, Belgium). The amount of IFN- $\gamma$ was determined in duplicate. The minimum measurable level of IFN- $\gamma$ was $0.03 \mathrm{IU} / \mathrm{ml}$.

\section{MTS assay}

When peripheral blood $\mathrm{CD} 4^{+} \mathrm{T}$ cells were cultured in the presence of each anti-IL-2R $\alpha, \beta$, and $\gamma$ blocking antibody to collect the culture supernatants for the assay of HTLV-I p19 antigen and IFN- $\gamma$ levels, the number of viable cells was simultaneously determined by a modified MTT assay as described previously (10). Briefly, after peripheral blood CD4 ${ }^{+}$ $\mathrm{T}$ cells $\left(1 \times 10^{5}\right.$ cells/well $)$ were cultured in the presence of $10 \mu \mathrm{g} / \mathrm{ml}$ of each anti-IL-2R antibody in 96-well flat-bottom plates for 48 hours, assays were performed by a nonradioactive cell proliferation method (Promega, Madison, WI). Cultures were studied in triplicate and the results were expressed as the mean optical density (OD).

\section{Statistical analysis}

The Wilcoxon-signed rank test was used for statistical analysis. Differences were considered statistically significant at $\mathrm{p}<0.05$.

\section{Results}

\section{Effect of anti-IL-2R blocking antibody on HTLV-I ex- pression on peripheral blood $C D 4^{+} T$ cells from HAM/TSP patients}

As shown in Fig. 1a, the treatment of peripheral blood $\mathrm{CD}^{+} \mathrm{T}$ cells from HAM/TSP patients with anti-IL-2R $\alpha$, but not anti-IL-2R $\beta$ or anti-IL-2R $\gamma$ blocking antibody, signifi- 
a)
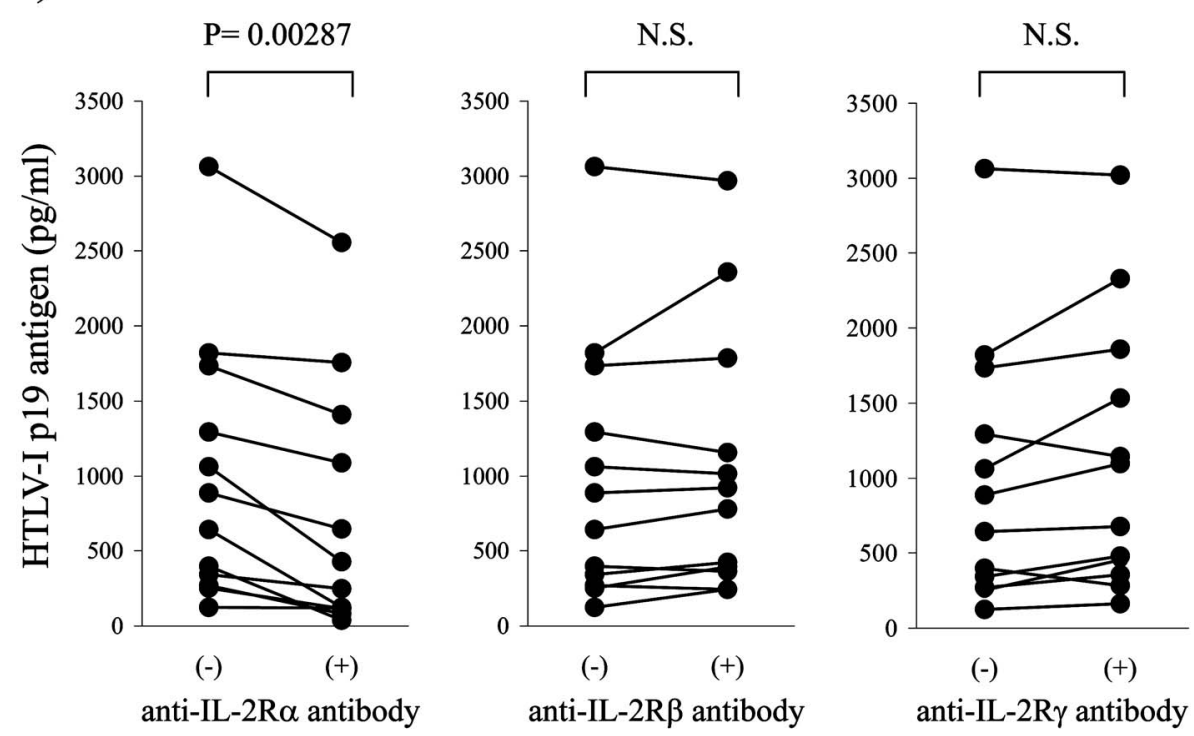

b)
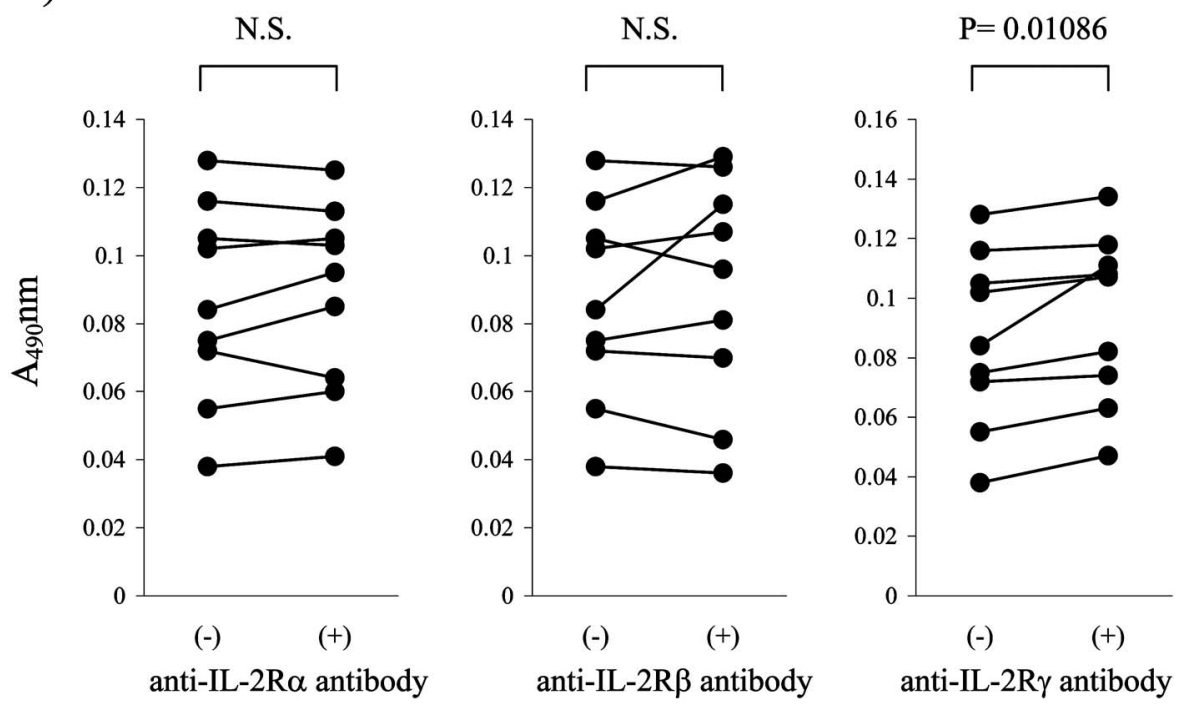

Figure 1. Anti-IL-2R $\alpha$ blocking antibody, but not anti-IL-2R $\beta$ or $\gamma$ blocking antibody, suppresses HTLV-I p19 antigen expression in peripheral blood $\mathrm{CD4}^{+} \mathrm{T}$ cells from HAM/TSP patients. a) Peripheral blood $\mathrm{CD}^{+} \mathrm{T}$ cells were cultured $\left(1 \times 10^{6} / \mathrm{ml}\right)$ in the absence or presence of $10 \mu \mathrm{g} / \mathrm{ml}$ of each anti-IL-2R $\alpha, \beta$, or $\gamma$ blocking antibody for 48 hours, and culture supernatants were collected. Levels of HTLV-I p19 antigen in each culture supernatant were measured by ELISA (n = 12). N.S.: not significant. b) Cell viability assays $(n=9)$. Peripheral blood $\mathrm{CD}^{+} \mathrm{T}$ cells from HAM/TSP patients were cultured at $1 \times 10^{5}$ /well, as in a) in 96-well plates. MTS assays were performed according to the manufacturer's instructions. Data were calculated as the mean OD titer in triplicate cultures at a wavelength of $490 \mathrm{~nm}$. N.S.: not significant.

cantly suppressed HTLV-I p19 antigen expression in peripheral blood $\mathrm{CD}^{+} \mathrm{T}$ cells of all HAM/TSP patients by about 2-90\%. The IL-2/IL-2R autocrine loop is considered to be one of the factors responsible for spontaneous proliferation in PBL in HAM/TSP patients $(6,7)$. Thus, to confirm that the anti-IL-2R $\alpha$ blocking antibody-induced suppression of
HTLV-I p19 antigen expression was not dependent on the inhibition of cell proliferation or on cytotoxicity by each anti-IL-2R blocking antibody, we checked the changes in cell viability of peripheral blood $\mathrm{CD}^{+} \mathrm{T}$ cells treated with each anti-IL-2R blocking antibody in MTS assays as indicators of cell proliferation. Not all the anti-IL-2R blocking an- 


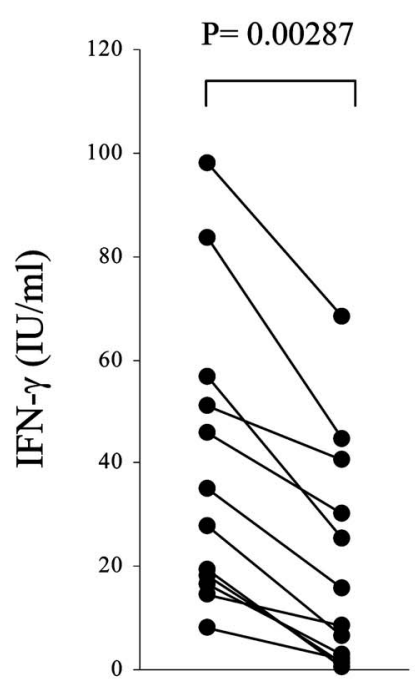

$(-)$

$(+)$

anti-IL-2R $\alpha$ antibody

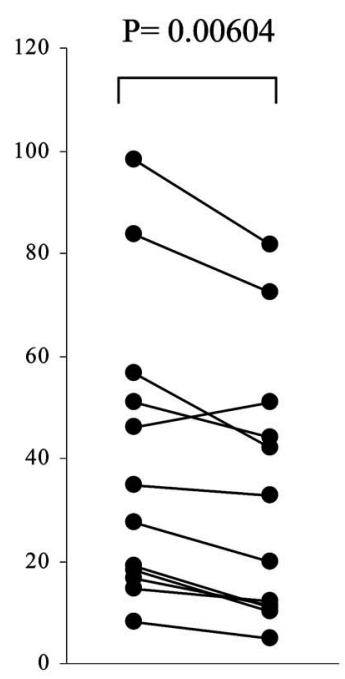

$(-)$

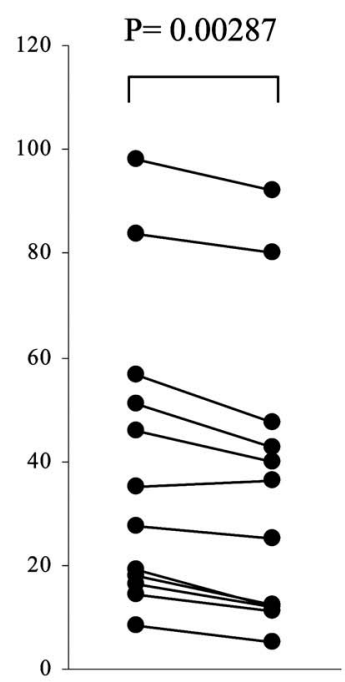

$(-)$

anti-IL-2R $\beta$ antibody

anti-IL-2R $\gamma$ antibody

Figure 2. All types of anti-IL-2R blocking antibody suppress IFN- $\gamma$ expression in peripheral blood $\mathrm{CD4}^{+} \mathrm{T}$ cells from HAM/TSP patients. Peripheral blood $\mathrm{CD4}^{+} \mathrm{T}$ cells were cultured $\left(1 \times 10^{6}\right.$ $/ \mathrm{ml}$ ) in the absence or presence of $10 \mu \mathrm{g} / \mathrm{ml}$ of each anti-IL-2R $\alpha, \beta$, or $\gamma$ blocking antibody for 48 hours, and culture supernatants were collected. IFN- $\gamma$ levels in each culture supernatant were measured by ELISA $(n=12)$.

tibodies suppressed cell viability in our experiment system, such as 48-hour culture (Fig. 1b), indicating that treatment with these antibodies did not inhibit cell proliferation.

\section{Effect of anti-IL-2R blocking antibody on IFN- $\gamma$ ex- pression on peripheral blood $\mathrm{CD}^{+} \mathrm{T}$ cells from HAM/TSP patients}

In the case of IFN- $\gamma$ expression, the treatment of peripheral blood $\mathrm{CD}^{+} \mathrm{T}$ cells from HAM/TSP patients with antiIL-2R $\alpha$ antibody significantly suppressed IFN- $\gamma$ expression in peripheral blood $\mathrm{CD}^{+} \mathrm{T}$ cells of all HAM/TSP patients by about $21-99 \%$ in the same manner as the effect on HTLV-I p19 antigen expression (Fig. 2). In addition, the treatment of peripheral blood $\mathrm{CD}^{+} \mathrm{T}$ cells from HAM/TSP patients with anti-IL-2R $\beta$ or anti-IL-2R $\gamma$ blocking antibody also significantly suppressed IFN- $\gamma$ expression in peripheral blood $\mathrm{CD}^{+} \mathrm{T}$ cells of all HAM/TSP patients (Fig. 2). As shown in Fig. 1b, these suppressive effects were not dependent on the inhibition of cell proliferation or on cytotoxicity by each anti-IL-2R blocking antibody. There was no discernible relationship between the suppressive effect for HTLV-I p19 antigen and IFN- $\gamma$ expression by the treatment with anti-IL-2R $\alpha$ antibody and the duration or severity of illness, or the serum level of anti-HTLV-I antibody titer.

\section{Discussion}

In this report, we showed that the blockade of IL-2/IL-2R by anti-IL-2R blocking antibody, particularly anti-IL-2R $\alpha$ blocking antibody, suppressed HTLV-I p19 antigen and IFN- $\gamma$ expression in peripheral blood $\mathrm{CD}^{+} \mathrm{T}$ cells from HAM/ TSP patients. IL-2/IL-2R and IL-15/IL-15R signaling, which is closely related to IL-2/IL-2R signaling, as an autocrine loop, was previously proposed as one of the most characteristic immunological abnormalities in HAM/TSP patients, such as spontaneous PBL proliferation (6). Indeed, although spontaneous PBL proliferation is an in vitro phenomenon, the disruption of IL-2/IL-2R or IL-15/IL-15R signaling might be an important target when considering therapeutic strategies for HAM/TSP patients $(7,8)$. Here, we have demonstrated that IL-2/IL-2R signaling is also an important signaling pathway for HTLV-I and IFN- $\gamma$ expression in peripheral blood $\mathrm{CD}^{+}{ }^{+} \mathrm{T}$ cells from HAM/TSP patients, suggesting that IL-2/IL-2R signaling involves Th1 activation based on high HTLV-I proviral load observed in PBL of HAM/TSP patients although a comparative study between HAM/TSP patients and other HTLV-I- infected individuals was not performed. In this study, although HTLV-I expression in peripheral blood $\mathrm{CD}^{+} \mathrm{T}$ cells of HAM/TSP patients was suppressed by treatment with anti-IL-2R $\alpha$ blocking antibody, but not by anti-IL-2R $\beta$ or IL-2R $\gamma$ blocking antibody, IFN- $\gamma$ expression in peripheral blood $\mathrm{CD}^{+} \mathrm{T}$ cells of HAM/TSP patients was suppressed by treatment with not only anti-IL$2 \mathrm{R} \alpha$ blocking antibody but also anti-IL-2R $\beta$ or IL-2R $\gamma$ blocking antibody. The reason for these discrepancies is unknown. However, the suppressive effect for IFN- $\gamma$ expression seemed more significant in the treatment with anti-IL-2R $\alpha$ blocking antibody than with anti-IL-2R $\beta$ or IL-2R $\gamma$ blocking antibody. Therefore, these phenomena may be based on the fact that the IL- $2 \mathrm{R} \alpha$ chain is a molecule involved in the initial stage of IL-2 binding in IL-2/IL-2R signal transduction 
(12).

Lehky et al previously reported that treatment with humanized anti-Tac (IL-2R) for HAM/TSP patients induces the decrease of HTLV-I proviral load in PBL (14). Although the exact mechanism of how the reduction of HTLV-I proviral load is induced is unclear, this treatment might inhibit the new infection of non-HTLV-I-infected cells from HTLV-Iinfected cells through the down-regulation of HTLV-I expression by the blockade of IL-2/IL-2R signaling in vivo, just as in our in vitro results, or alternatively induce apoptosis of HTLV-I-infected cells by the long-term inhibition of IL-2/IL-2R signaling in vivo.

In conclusion, we have demonstrated the involvement of
IL-2/IL-2R signaling in HTLV-I and IFN- $\gamma$ expression in peripheral blood $\mathrm{CD}^{+} \mathrm{T}$ cells from HAM/TSP patients. The down-regulation of both HTLV-I expression and Th1 activation is an important condition when considering HAM/TSP treatment. Therefore, the IL-2/IL-2R signaling pathway may be a potential target in therapeutic strategies for HAM/TSP.

This work was supported in part by a Neuroimmunological Disease Research Committee Grant from the Ministry of Health, Labour and Welfare, Japan and by a Grant-in-Aid for Scientific Research (no. 16590834 to T.N.) from the Ministry of Education, Science, Sports, and Culture of Japan.

\section{References}

1. Osame M, Matsumoto M, Usuku K, et al. Chronic progressive myelopathy associated with elevated antibodies to human Tlymphotropic virus type I and adult T-cell leukemia-like cells. Ann Neurol 21: 117-122, 1987.

2. Iwasaki Y. Pathology of chronic myelopathy associated with HTLV-I infection. J Neurol Sci 96: 103-123, 1990.

3. Osame M. Pathological mechanisms of human T-cell lymphotropic virus type I-associated myelopathy (HAM/TSP). J Neurovirol 8 : 359-364, 2002.

4. Poiesz BJ, Ruscetti FW, Gazdar AF, et al. Detection and isolation of type $\mathrm{C}$ retrovirus particles from fresh and cultured lymphocytes of a patient with cutaneous T-cell lymphoma. Proc Natl Acad Sci USA 77: 7415-7419, 1980.

5. Inoue J, Seiki M, Taniguchi $T$, et al. Induction of interleukin 2 receptor gene expression by $\mathrm{p} 40 \mathrm{x}$ encoded by human T-cell leukemia virus type I. EMBO J 5: 2883-2888, 1986.

6. Itoyama Y, Minato S, Kira J, et al. Spontaneous proliferation of peripheral blood lymphocytes increased in patients with HTLV-Iassociated myelopathy. Neurology 38: 1302-1307, 1988.

7. Tendler CL, Greenberg SJ, Blattner WA, et al. Transactivation of interleukin 2 and its receptor induces immune activation in human T-cell lymphotropic virus type I-associated myelopathy: pathogenic implications and a rationale for immunotherapy. Proc Natl Acad Sci USA 87: 5218-5222, 1990.

8. Azimi N, Jacobson S, Leist T, Waldmann TA. Involvement of IL-
15 in the pathogenesis of human $\mathrm{T}$ lymphotropic virus type Iassociated myelopathy/tropical spastic paraparesis: implication for therapy with a monoclonal antibody directed to the IL-2/15R $\beta$ receptor. J Immunol 163: 4064-4072, 1999.

9. Nakamura T. Immunopathogenesis of HTLV-I-associated myelopathy/tropical spastic paraparesis. Ann Med 32: 600-607, 2000.

10. Fukushima $N$, Nishiura $Y$, Nakamura $T$, Yamada $Y$, Kohno $S$, Eguchi K. Involvement of p38 MAPK signaling pathway in IFN- $\gamma$ and HTLV-I expression in patients with HTLV-I-associated myelopathy/tropical spastic paraparesis. J Neuroimmunol 159: 196-202, 2005.

11. Crawley JB, Rawlinson L, Lali FV, Page TH, Saklatvala J, Foxwell BMJ. T cell proliferation in response to interleukin 2 and 7 requires p38MAP kinase activation. J Biol Chem 272: 1502315027, 1997.

12. Ellery JM, Nicholls PJ. Alternate signalling pathways from the interleukin-2 receptor. Cytokine Growth Factor Rev 13: 27-40, 2002.

13. Osame M. Review of WHO Kagoshima meeting and diagnostic guidelines for HAM/TSP. In: Human Retrovirology. HTLV. Blattner WA, Ed. Raven Press, New York, 1998: 191-197.

14. Lehky TJ, Levin MC, Kubota R, et al. Reduction in HTLV-I proviral load and spontaneous lymphoproliferation in HTLV-Iassociated myelopathy/tropical spastic paraparesis patients treated with humanized anti-Tac. Ann Neurol 44: 942-947, 1998.

(C) 2007 The Japanese Society of Internal Medicine http://www.naika.or.jp/imindex.html 